\title{
TOWARDS INNOVATIVE GEOSPATIAL TOOLS FOR FIT-FOR-PURPOSE LAND RIGHTS MAPPING
}

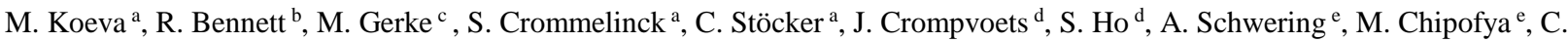

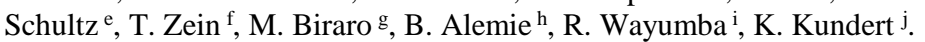

\author{
${ }^{a}$ University of Twente (ITC), Netherlands, 7514AE Enschede, The Netherlands - (m.n.koeva, s.crommelinck, \\ e.c.stocker@utwente.nl) \\ ${ }^{\mathrm{b}}$ Swinburne Business School, Swinburne University of Technology, Victoria 3122 Australia - rohanbennett@ swin.edu.au \\ ${ }^{c}$ Institute of Geodesy and Photogrammetry, Technical University Braunschweig, 38106 Braunschweig, Germany - m.gerke@tu- \\ bs.de \\ ${ }^{d}$ Katholieke Universiteit Leuven, 3000 Leuven, Belgium - (joep.crompvoets, serene.ho@ soc.kuleuven.be) \\ e Westfälische Wilhelms-Universität, 48149 Muenster, Germany - (schwering, chipofya, schultzc@uni-muenster.de) \\ f Hansa Luftbild AG, 48147 Münster, Germany - zein@ hansaluftbild.de \\ g Department of Land Administration and Management, INES - Ruhengeri - biraro.mireille@gmail.com \\ h Bahir Dar Univeristy, Bahir Dar, Ethiopia - berhanu_k2003@yahoo.com \\ i Technical University of Kenya, 00200, Nairobi, Kenya - rwayumba@gmail.com \\ ${ }^{\mathrm{i}}$ Esri Rwanda Ltd., 00200, KG 666, Rwanda-k.kundert@esri.rw
}

Commission IV, WG IV/4

KEY WORDS: Geocloud, Horizon2020, European Union, UAV, Land Administration, Cadastral Mapping

\begin{abstract}
:
In large parts of sub Saharan Africa it remains an ongoing challenging to map millions of unrecognized land rights. Existing approaches for recognizing these rights have proven inappropriate in many cases. A new generation of tools needs to be developed to support faster, cheaper, easier, and more responsible land rights mapping. This is the main goal of its4land, an European Commission Horizon 2020 project that aims to develop innovative tools inspired by the continuum of land rights, fit-for-purpose land administration, and cadastral intelligence. its4land is using strategic collaboration between the EU and East Africa to deliver innovative, scalable, and transferrable ICT solutions. The innovation process incorporates a broad range of stakeholders and emergent geospatial technologies, including smart sketchmaps, UAVs, automated feature extraction, as well as geocloud services. The aim is to combine innovative technologies, capture the specific needs, market opportunities and readiness of end-users in the domain of land tenure information recording in Eastern Africa. The project consists of a four year work plan, €3.9M funding, and eight consortium partners collaborating with stakeholders from six case study locations in Ethiopia, Kenya, and Rwanda. The major tasks include tool development, prototyping, and demonstration for local, national, regional, and international interest groups. The case locations cover different land uses such as: urban, peri-urban, rural smallholder, and (former) pastoralist. This paper describes the project's activities within the first 18 months and covers barriers discovered, lessons learned and results achieved.
\end{abstract}

\section{INTRODUCTION}

The results of many existing ICT-based approaches focused on land tenure recording in sub Saharan Africa are deviating from experts expectations. Challenges include, amongst others, incomplete recordation, and unresolved and/or escalated disputes that exacerbate, small and large-scale investments. Such situations can be observed in various developing regions, with sub Saharan Africa being one example (Zevenbergen et al., 2013).

There is a clear need for innovations to face the challenge of mapping in a fast and cheap manner, the $70 \%$ of unrecognized land rights. Some developed tools such as those derived by the
Global Land Tool Network (GLTN), have successfully combined conventional land administration design and project implementation. Several tools (e.g. STDM) show how fit-forpurpose land administration can be applied in practice (UNHabitat, 2012). The next generation of land tools, which build upon ideals of responsibility, scalability and the ability to transcend conventional institutions, technologies, and methods, are quickly emerging (de Vries et al., 2015).

The project 'its4land' aims to create seven new innovative tools that further support faster, cheaper, easier, and more responsible land rights mapping (EC, 2017; Bennett et al., 2017). The tools are inspired by the continuum of land rights, fit-for-purpose land administration, and cadastral intelligence. More specific, 
the work combines an ICT innovation process - involving a broad range of stakeholders - with emergent geospatial technologies, including smart sketchmaps, Unmanned aerial vehicles (UAVs), automated feature extraction, and geocloud services. The project seeks to enable tool combinations that are both end-user and market responsive. Moreover, the tools seek to support so-called top-down (formal land registration processes) and bottom-up approaches (informal community based land resource documentation).

This paper describes the project's activities within its first year including barriers discovered, lessons learned and results achieved. Risks and future opportunities are also described. The case study locations across the three Eastern African countries are introduced. Preliminary results for each phase of the project are presented. At the end, conclusions and ideas for future development are shared.

\section{BACKGROUND}

The duration of its4land is four years. The provided funding is $€ 3.9 \mathrm{M}$ for all eight consortium partners which are from Belgium (KU Leuven), Ethiopia (Bahir Dar University), Germany (University of Muenster; Hansa Luftbild), Kenya (Technical University of Kenya) the Netherlands (University of Twente), and Rwanda (INES Ruhengeri; ESRI Rwanda). The project is a 'Research and Innovation Action' and is formally governed through the European Commission's Horizon 2020 Industrial Leadership program. More specifically the 'Leadership in enabling and industrial technologies Information and Communication Technologies ICT (H2020EU.2.1.1.)', under the call H2020-ICT-2015. The specific topic is 'International partnership building in low and middle income countries’ ICT-39- 2015.

The project started in February 2016. The consortium is working with stakeholders from six case study locations in Ethiopia, Kenya, and Rwanda. The work primarily consists of designing, prototyping, and demonstrating the tools to local, national, regional, and international stakeholders. The case locations include a mix of livelihoods and landscapes such as urban, peri-urban, rural smallholder, and (former) pastoralist areas. The focus for the project is different in each case location. The work in Kenya (Kisumu and Kajiado) is focused on adapting tools to enable mapping of pastoralist land rights and layered disputes. In Rwanda (Musanze), the work mainly consists of developing approaches that can support updating, at scale, land rights documents and maps. In Ethiopia (Bahir Dar and Amhara Region), the interest is in developing approaches that improve plot recordation of urban smallholder and dwellers.

As part of the global aim of the project can be also considered the idea of reinforcing strategic collaboration between the EU and Eastern Africa. We also aim to demonstrate how multisectorial, multi-national, and multidisciplinary design work can take place. The consortium includes SMEs and researchers from three EU countries and three East African countries. The transdisciplinary work also develops supportive models for governance, capacity development, and business capitalization. Gender sensitive analysis is also being incorporated.

Independent to European Commission oversight, the project includes a dedicated Advisory Board, a Valorisation Panel, and communications and dissemination channels.

\section{CASE STUDY LOCATIONS}

\subsection{Rwanda}

Beginning of 2000 in Rwanda there was a significant policy and legal reform with regard to land. The aim was to regularize all existing lands under private, leasehold, and state tenures. The policies were seen as positive by the international land sector with regard to gender recognition, minority group recognition, and overall equality (Biraro, 2015a).

Part of this land reforms involved a nationwide adjudication, surveying, and recording program. The Rwandan Natural Resources Authority (RNRA) is responsible for the maintenance of the land records including spatial and textual components. It was a huge success to start this reform. In order to cover maximum area faster and cheaper, hardcopies of orthophotos produced from high-resolution aerial images were used, or satellite images (depending on availability). Many local inhabitants were employed by the project and trained. The achieved accuracy was low due to the aim to record as fast as possible maximum coverage. Most boundaries were digitized within $1-5 \mathrm{~m}$ of the 'true' position.

The remaining challenge is the maintenance and proper recording in the new system (Biraro, 2015b). The challenge of land information updating has direct impact on spatial planning and urbanization strategies in Rwanda. This is discussed by Ho et al (2017) in terms of national policies for the realisation of six secondary cities and the Spatial Development Framework to support decision-making. Especially in Musanze, up-to-date land information is needed to balance the demand for urbanization and expanded tourism. A district land use plan is established. However, there are some economic and administrative factors that affect its realisation. Current mechanisms and processes do not actively facilitate data integration with the cadastral map to support decision-making Ho et al. (2017). The District needs to adapt to its current resource capacity. It was discovered that there is missing general topological information, such as buildings, plots and visible infrastructure, etc., that is fundamental to planning and development.

The challenge is to determine if and how geospatial tools might be used to improve the speed, cost and quality of land information updates in both urban and rural Rwanda. The usage of UAVs in this context was discussed worldwide, but also investigated for Rwanda as well (Koeva et al., 2016).

\subsection{Kenya}

In Kenya, its4land's efforts are focused on finding best solutions for recognizing pastoralist land rights of Lengoiboni et. al (2011). In their research it was stated that pastoralism constitute $84 \%$ of the country's total land use in Kenya. The areas support about one third of the Kenyan population ( \pm 10 million people), account for more than $80 \%$ of the country's ecotourism, and $75 \%$ of the wildlife population. The problem is that land pastoralist's pass through land, which was privatized in the form of parcels and group ranches.

In $2016 / 2017$ as a result of privatization of land rights that overlooked the existence of "customary right of movement across the land', a lot of problems were observed: spatial information about the tracks and corridors often remain as 
undocumented mental maps. This has led to gaps in land information systems or in land use planning. The situation is becoming even worse: land is continuously being surveyed, demarcated and allocated for private purposes.

These challenges are result from the conflict between modernisation and cultural preservation, urbanisation, and poor land governance systems that have resulted in poor quality land information suffering from a lack of transparency. Therefore, the challenge is to develop tools to record and raise awareness about customary land rights and holders. In order to contribute to better planning this information should be included, organized and maintained in a local land information system.

\subsection{Ethiopia}

In Ethiopia, its4land is working on two different cases: periurban and rural landscapes. Each has its own problems and challenges in terms of land management. Bahir Dar is one of the fastest growing cities in Ethiopia, which consists mainly of periurban areas. The growth is taking place in all directions. An administrative vacuum is experienced especially in places, where urban areas meets rural - peri-urban. In contrast to many other African countries, Ethiopia separates rural and urban land administration amongst different institutions. However, the boundary between landscapes is not always clear. In such areas, higher levels of informality and non-statutory land occupation can be observed. Urban authorities, donors and stakeholders are working to establish cadastres and land administration systems for the urban areas. Different combinations of tools, including image-based approaches (orthophotos) are being adopted. However, the usage of high-resolution UAV images and geocloud storage are seen as potential solutions to improve existing designs.

Regarding rural contexts, the selected case study area is Robit Bata rural district $\left(\right.$ Kebele $\left.^{1}\right)$ which is close to Bahir Dar $(20 \mathrm{~km})$. It has high level of land degradation and land fragmentation. For reducing poverty and enhancing land productivity, land consolidation is seen as solution. However, responsible land consolidation demands sound land records and participatory approaches (Bennett and Alemie, 2016). This type of land responsible consolidation is hardly explored in Ethiopia. Therefore, in the rural area there is a clear opportunity for providing local stakeholders with information such as: up-todate images and tools for recording land data in help of consolidation process.

\section{WORK PHASES AND RESULTS}

\subsection{Get needs}

The first phase of its4land focuses on contextualization, based on the three case study locations. Specifically, the aim is to understand and identify the needs of stakeholders in the land sector and how its4land's technologies meet these needs. The project distinguishes between primary and secondary stakeholders: the first are defined to be those who have a direct role in acquiring, recording, managing and distributing land tenure information and the second, those who only re-use or add value to land tenure information to provide products and services. Stakeholders' needs are defined to be those practical information requirements, which are necessary to support their individual or organizational aims relative to their position in the land tenure information system.

For the project, six main stakeholder group classes were defined:

- public sector entities (land administration specific)

- public sector entities (adjacent policy domains or public organizations)

- non-statutory entities

- private sector entities

- NGOs/not-for-profit/donors

- research and development partners

For each country, key stakeholders have been identified both nationally and in the context of the case study locations. Therefore, analysis of each country for adopting and using the identified its4land technologies need to be done. The potential market opportunities associated with the new technology and used data were also identified. The results from initial exploratory interviews in 2016 reveal local needs and challenges. Meanwhile, in 2017, participatory data capture activity is being completed in all three case countries. Data is being collected using a series of stakeholder group-based workshops employing the Nominal Group Technique (NGT). This group interview form enables structured problem-solving or idea-generation. Therefore, ideas are initially generated individually, but then as a group, gathered, combined and rankordered in terms of priority. As a data collection method, it builds on expert representation across stakeholder groups, and offers strong reliability and validity compared to other interviewing methods (Langford, 1994; Langford, Schoenfeld, \& Izzo, 2002) as well as minimal bias from facilitators (Lloyd, 2011). Detailed analysis is expected for the obtained results.

\subsection{Draw and make}

There are four technically oriented design activities in its4land. The first is related with developments of sketch-map digitization and metric map generation. This approach is seen as highly supportive for bottom-up land records documentation. It is suitable especially where land tenure relationships are recorded from the perspective of land users. The work will be using inclusive, community driven activities. Therefore, land tenure records need to be modelled using concepts of land tenure according to the local to specific communities. The spatial component of land tenure records can be obtained as hand sketched maps created by the communities themselves. The state of the art in analysing such maps involves manual digitization on top of base topographic maps that is usually a time consuming and skill dependent process.

The its4land smart sketch maps tool builds from previous work (Schweing et. al, 2014) and automates the digitization process. Extraction of both spatial and non-spatial information in a sketch map, and integration of the base map is performed. The aim is to support non-governmental organizations such as Namati and Water Aid in the use of sketching as a reliable method for map creation. Figure 1 shows an early prototype of a user interface of an alignment between a sketch map, base map comprising a satellite image (adapted for demonstrative purposes from Google Earth) and vector data overlaid on top of the image.

\footnotetext{
${ }^{1}$ Kebele is the lowest administrative unit in Ethiopia
} 

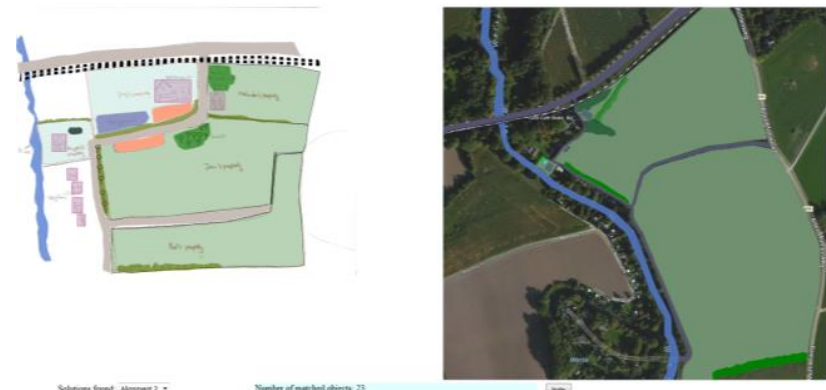

Figure 1. Prototype user interface for exploring possible alignments of a sketch map with a vector-raster overlay (http://chipofya.staff.ifgi.de/tech4land/alignment_demo.html)

For Smart Sketch Maps tool development the focus is on:

- developing a domain model of concepts used in the description of land resources and tenures within localized contexts (e.g. at community level or within cultural groups)

- developing spatial models for representing sketch maps as records of land tenure information

- developing methods for recognition of land tenure sketch maps and for embedding the sketch maps within existing spatial data sets (sketch map alignment)

For processing Smart Sketch Maps, the system will rely on knowing in advance the types of symbols and strokes that are expected in any sketch. This approach is much better than working with unstructured, freehand sketches. Therefore, a visual sketch language was developed for this task. The visual language is based on a specialised domain model. It consists of documents and spatial concepts that users (e.g. pastoralists) consider important for their everyday activities, describing land and land relationships. The system had to be adapted to local cultural contexts of different communities by adapting its domain model.

During field visits, data is collected to support the design of an appropriate visual language. The challenges in this aspect are interpreting the data that is in local languages and may include concepts that are out of our experiences. Work on exploring more intuitive visualizations to improve user experience and to realize an effective Smart Sketch Maps solution is still going on

\subsection{Fly and create}

"Fly and Create" is a technical its4land tool related to the use of UAVs in land administration workflows. Unmanned aerial vehicles - UAVs are evolving as a tool for alternative land tenure data acquisition approaches, amongst others (ICAO, 2011). Developments in photogrammetry have created new opportunities for low cost, reliable, user-friendly and lightweight solution for collecting timely, tailored, detailed and high-quality geospatial information using UAVs. Even they seem to be a very promising technology, some constraints exists. Some of them are inexistence of regulatory frameworks and undeveloped ground truthing strategies. One of the major questions concerns the applicability and reliability of UAVs for land administration purposes.

The aim of this phase of the project is to design, test, and validate a UAV-driven land administration workflow. In order to reach this goal, we studied policy and legal developments regarding UAV regulations (Stocker et. al, 2017). Based on these outcomes detailed guidelines for efficient operational UAV workflows that are adapted to stakeholder needs will be delivered. What is needed for UAV based workflow is shown in Figure 2.

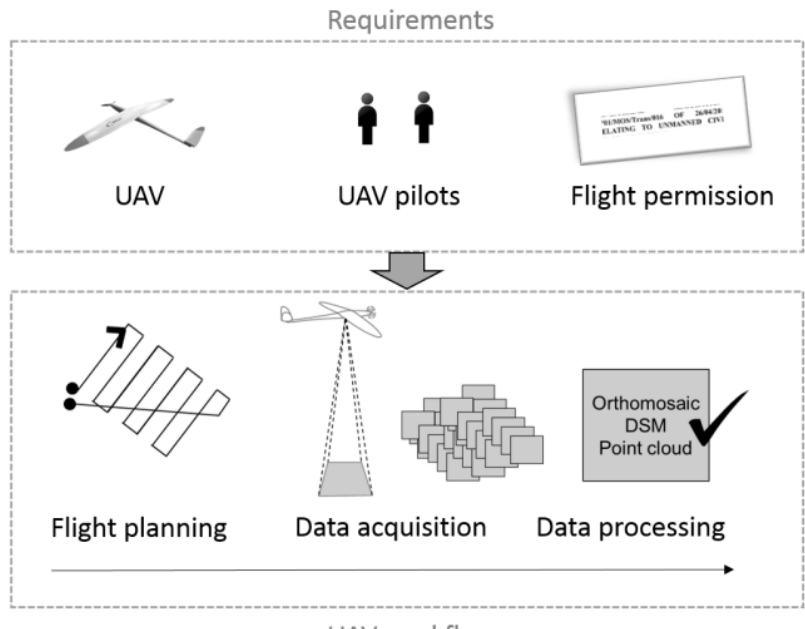

UAV workflow

Figure 2. Key ingredients for a UAV-based land tenure recording tool

After a detailed analysis of the existing UAVs, a fixed wing UAV DT 18 PPK by DelairTech was selected. One of the main reasons was that it specialization for mapping large areas. The flight time can be up to $90 \mathrm{~min}$, which means that during one flight the UAV can capture more than $1 \mathrm{~km}^{2}$. This UAV allows direct georeferencing which is minimizing the time and costs for ground truthing activities. The obtained accuracies after tests performed in Toulouse were $5-8 \mathrm{~cm}$.

Each of the above mentioned African countries received the same UAV and pilot training. The third important prerequisite for the successful commencement of UAV data capture activities are the flight permissions. After performing a global overview of UAV regulations it was concluded that nearly one third of all countries have regulatory documents in place. In Rwanda there are already enacted UAV regulations (Rwanda Civil Aviation Authority 2016), however in Kenya and Ethiopia, regulations are still pending. Even Rwanda has regulations, we encountered cumbersome administrative procedures. Further challenges are expected in acquisition processes in East Africa. This concerns mainly the selection of appropriate sites for takeoff and landing, environmental challenges to the UAV equipment and the dependency on UAV pilots. Some of the other benefits observed for the chosen UAVs are the useful functions such as adaptive flight planning and image previews in order to design suitable UAV workflows as an appropriate land tool.

\subsection{Automate it}

This innovation aims to design and implement a tool for automated boundary delineation for cadastral mapping. This is done by automatically extracting visible cadastral boundaries from UAV data. The tool will allow editing and finalizing those boundaries. It aims to improve current mapping procedures in terms of cost, time and accuracy. This innovation is based on the assumption that a large portion of cadastral boundaries is physically manifested through objects such as hedges, fences, stone walls, tree lines, roads, walkways or waterways. Those 
visible boundaries bear the potential to be extractable with computer vision methods (Bennett et al., 2010; Crommelinck et al., 2016; Zevenbergen and Bennett, 2015). The automatically extracted outlines require further (legal) adjudication that allows incorporating local knowledge from a human operator.

In past work, a hypothetical generalized workflow for the automatic extraction of visible cadastral boundaries has been proposed (Crommelinck et al., 2016). It was derived from 89 studies that extract objects related to those manifesting cadastral boundaries from high-resolution optical sensor data. The synthesized workflow consists of image segmentation, line extraction and contour generation (Figure 3).

For image segmentation, globalized probability of boundary $(\mathrm{gPb})$ contour detection (Figure 4) was found to be applicable for an initial detection of visible boundaries. However, the global optimization of the method did not allow to process large images. Therefore the UAV data was reduced in resolution, which lead to a reduced localization quality (Crommelinck et al. 2017b). To improve the localization quality and to verify initially detected candidate boundaries is the aim of the proceeding workflow step: for line extraction, simple linear iterative clustering (SLIC) superpixels (Figure 5) were found to coincide largely with object boundaries in terms of completeness and correctness (Crommelinck et al., 2017a). For contour generation, $\mathrm{gPb}$ contour detection and SLIC superpixels are combined and processed in a semi-automatic tool that allows a subsequent final delineation of cadastral boundaries. The tool is implemented as a publicly available QGIS plugin (Crommelinck, 2017). This final step is the focus of ongoing work. Figure 4 summarizes the described workflow consisting of $\mathrm{gPb}$ contour detection (Figure 4), SLIC superpixels (Figure 5) and its combination, which is still under development.

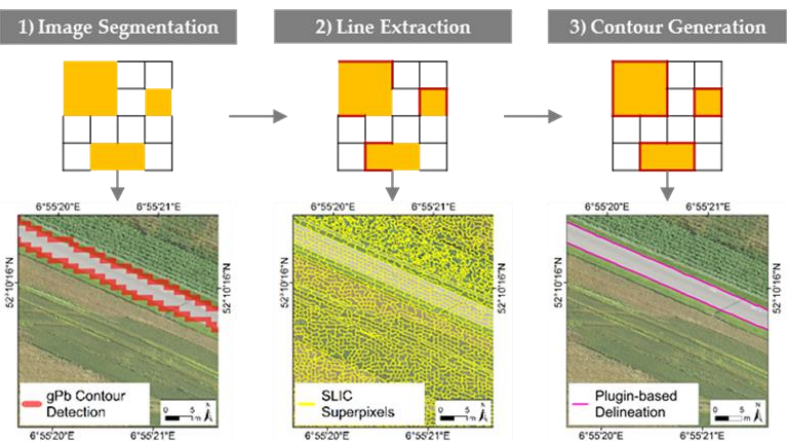

Figure 3. Sequence of commonly applied workflow steps proposed in (Crommelinck et al., 2016) to extract objects related to those manifesting cadastral boundaries from highresolution optical sensor data

For the first and second workflow step, state-of-the-art computer vision approaches have been evaluated separately and determined as efficient for UAV-based cadastral mapping (Crommelinck et al., 2017a; Crommelinck et al., 2017b). The third workflow step as well as its combination with the proceeding steps are designed and implemented in ongoing work.

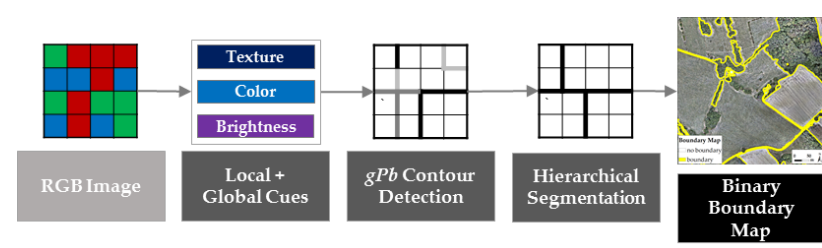

Figure 4. Processing pipeline of globalized probability of boundary $(\mathrm{gPb})$ contour detection and hierarchical image segmentation resulting in a binary boundary map containing closed segment boundaries.

The approach is described in (Arbelaez et al., 2011). The source code is publicly available in (Arbeláez et al., 2011).

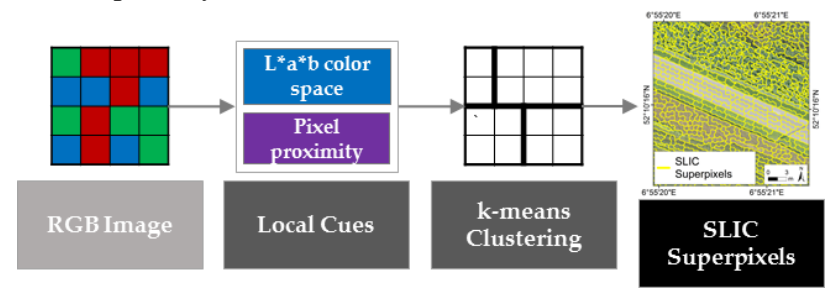

Figure 5. Processing pipeline of simple linear iterative clustering (SLIC) resulting in agglomerated groups of pixels, i.e., superpixels, whose boundaries outline objects within the image

The approach is described in (Achanta et al., 2010) and extended in (Achanta et al., 2012).

\subsection{Publish and share}

During this phase of our work, we aim to prove a concept for the integration of data, workflows, publication, and sharing of land tenure information. For this reason, the results from the previous phases (UAV data collection, smart sketchmaps and automatic feature extraction) are needed in order to be integrated. This adapted version of the land administration domain model (LADM) is used as a basis for organizing and integrating data and processes.

Current work is focused on the following tasks:

- Integration of UAV and mobile data acquisition and data processing and analysis of the methodologies of (semi) automated feature extraction. The intended system will provide the framework for integrating geospatial data into standard open source GIS

- Integration of qualitative information from sketch maps with quantitative information in order to represent land with cadastral boundaries. In this task an extension for quantitative databases will be developed. Then the qualitative layer with additional descriptive information from sketch maps will be integrated into one database

- Developing and implementing a workflow based on the output from LADM based LAS. All data can later be transferred to a central cadastral database

- Development and implementation of a LIS by Hansa Luftbild based on LADM information derived from sketch maps.

- Training of local partners to use the system.

Hansa Luftbild is the leader for this task working in collaboration with the partners in the Netherlands, Germany, Ethiopia, Kenya and Rwanda. The two European partners support in providing inputs to design the system architecture according to their respective. The African partners will provide 
end-user access, field locations for testing, and expertise on functionality and qualitative testing.

We consider the acceptance of open source software by developing countries to be crucial when establishing land administration systems in such countries. In addition, we think that our work will positively impact the availability of land administration system to developing countries not just at national level, but also at local level.

\subsection{Govern and grow}

its4land is also focused on investigation of potential strategies for the governance of the developed tools. For this phase of the project input information is needed in order to follow the best methodology for applying the new technologies. More concret, outcomes regarding the country contexts, the types of existing tenure systems, the operation of current government systems and related institutions that regulate land tenure and land administration systems, and proposed workflows of the new tools are used as input for establishing sustainable governance models. The aim is to understand how to coordinate and manage the use of the proposed technologies to deliver maximum benefits.

The governance of the innovative geospatial tools is seen as critical to enable their longer-term success. This requires assessment not only on how these innovative tools can be useful for improving a specific land issue, but also focusing on all stakeholders and end-users interests. This will also lead to recommendations in terms of capacity development across institutional and technical domains. The research on this is still in the beginning phase. The plan is to work on theoretical, empirical and applied parts: based on insight information derived from interviews in Ethiopia, Kenya and Rwanda. Governance and capacity development models will be developed, tested and valorised.

\subsection{Capitalize}

This part of the research involves the development of a sustainable business model for commercialization of the integrated suite of land tenure recording tools, within the enduser markets. Using the results from the previous phases of the project this work will combine actor preferences (local communities, government, investors, and small and mediumsized enterprises [SME]), with products and spatial aspects. This will be done in order to define a range of business model scenarios for the different case locations. The idea is that the results of the project will be commercialized and marketed as a product or service. It will be offered to the public.

To demonstrate the results the largest geospatial industry trade shows (e.g. ESRI user conference, GeoBusiness (UK), Intergeo (Ger) will be used. The tools will be made freely available online. Subsequently, they will be linked to open source communities already working on land tool developments.

This phase includes the following three major tasks:

- Developing and choosing a business model that best fits the product or services resulting from the innovations. The input data from previous phases will provide an initial concept for the business model, which will be designed to include the necessary building blocks. As an example, such block can be value propositions, distribution channels, customer relationships, value configurations, core capabilities, partner network, cost structure, and revenue model.
- Creating business plan constructions, which will cover the development of the product descriptions and the advantages of the product when compared to other technologies. This will include: market opportunity, the financial projections and funding requirements. The business plan will underline to potential customers the gains, which they will make through acquiring the product. It will also include the marketing approach and strategy used in order to bring the product to the customers.

- Launching the product and services

\section{CONCLUSIONS}

The major tasks completed in the first year of the project were related with developing appropriate data collection instruments, piloting and demonstration activities. The work was focused in the six case study locations across the three Eastern African countries. In each country, both urban and rural contexts were pursued. In addition to the target countries, test locations in Germany (Amtsvenn) and France (Toulouse) were used to test data acquisition methods with UAVs and to assess the preliminary results.

Its4land is moving beyond the state of the art in all its intended impact areas: partnership, building, ICT advances, end-user understandings, enhancing innovation capacity, revealing global markets, and supporting environmental and social conditions. During its first year, most impact was achieved in terms of partnership building and cooperation - and initial engagement. What is following is development in terms of ICT-advances, innovation capacity, knowledge sharing, global market access, and potential social and environmental impact. Overall the results of the project are supporting not only Eastern African local communities, governments, NGOs, and academia - but, the EU technology, donor, SME, and government sectors by advancing EU geo ICT strengths, creating new and exploitable land tenure tools, strengthening EU-Eastern African partnerships (government/private/NGO) - and in the longer run a more socially and environmentally stable Eastern Africa.

\section{ACKNOWLEDGEMENTS}

This research was funded within its4land, which is part of the Horizon 2020 program of the European Union, project number 687828. We acknowledge the contribution of project partners and authors of "Building Third Generation Land Tools: Its4land, Smart Sketchmaps, UAVs, Automatic Feature Extraction, And The Geocloud", World Bank conference, Washington.

\section{REFERENCES}

Achanta, R., Shaji, A., Smith, K., Lucchi, A., Fua, P., \& Süsstrunk, S., 2010. Slic superpixels. EPFL-REPORT-149300.

Achanta, R., Shaji, A., Smith, K., Lucchi, A., Fua, P., \& Süsstrunk, S., 2012. SLIC superpixels compared to state-of-theart superpixel methods. IEEE transactions on pattern analysis and machine intelligence, 34(11), pp. 2274-2282.

Arbelaez, P. Maire, M., Fowlkes, C., Malik, J., 2011. Contour detection and hierarchical image segmentation. Pattern Analysis and Machine Intelligence 2011, 33, pp.898-916. 
Arbelaez, P. Maire, M., Fowlkes, C., Malik, J., 2011. Contour detection and image segmentation resources. https://www2.eecs.berkeley.edu/Research/Projects/CS/vision/gr ouping/resources.html (10 Nov. 2016).

Bennett, R., Kitchingman, A., \& Leach, J., 2010. On the nature and utility of natural boundaries for land and marine administration. Land use policy, 27(3), pp.772-779.

Bennett, R., Gerke, M., Crompvoets, J., Ho, S., Schwering, A., Chipofya, M. \& Wayumba, R., 2017. Building Third Generation Land Tools: Its4land, Smart Sketchmaps, Uavs, Automatic Feature Extraction, And The Geocloud, World Bank conference, Washington.

Bennett, R. M., \& Alemie, B. K., 2016. Fit-for-purpose land administration: lessons from urban and rural Ethiopia. Survey Review, 48(346), pp.11-20.

Biraro, M., Bennett, R. M., \& Lemmen, C., 2015a. Accelerated Land Administration Updates. In: Advances in Responsible Land Administration, pp. 145-162.

Biraro, M., Khan, S., Konguka, G., Ngabo, V., Kanyiginya, V., Tumusherure, W., Potel, J., 2015b, Final Report of Study on the access to the land tenure administration system in Rwanda and the outcomes of the system on ordinary citizens. LAND Project, USAID, Kigali, Rwanda.

Crommelinck, S., Bennett, R., Gerke, M., Nex, F., Yang, M., Vosselman, G., 2016. Review of Automatic Feature Extraction from High-Resolution Optical Sensor Data for UAV-Based Cadastral Mapping. Remote Sensing, 8, pp.1-28.

Crommelinck, S., 2017. QGIS Python Plugins Repository: BoundaryDelineation.http://plugins.qgis.org/plugins/Boundary Delineation/ (13 June 2017).

Crommelinck, S., Bennett, R., Gerke, M., Koeva M.,Yang, M. Y., \& Vosselman, G., 2017a. SLIC Superpixels for Object Delineation from UAV Data. UAVg conference, Bonn, Germany, pp.1-8.

Crommelinck, S., Bennett, R., Gerke, M., Yang, M. Y., \& Vosselman, G., 2017b. Contour Detection for UAV-Based Cadastral Mapping. Remote Sensing, 9(2), pp.1-13.

de Vries, W. T., Bennett, R. M., \& Zevenbergen, J., 2015. Toward Responsible Land Administration. In Advances in Responsible Land Administration, pp. 3-14.

EC., 2017. Its4land: Geospatial technology innovations for land tenure security in East Africa, Community Research and Development Information Service, European Commission, Brussels http://cordis.europa.eu/project/rcn/199024_en.html (14 Feb 2017).

Enemark, S., Bell, K.C., Lemmen, C., McLaren, R., 2014. FitFor-Purpose land administration. International Federation of Surveyors: Frederiksberg, Denmark, p. 42.

Google earth V7.1.7.2606., 2016. Münster, Germany. 51 ${ }^{\circ} 58^{\prime}$ $22.67^{\prime \prime} \mathrm{S}, 7^{\circ} 42^{\prime} 18.69^{\prime \prime}$ E, Eye alt $1.09 \mathrm{~km}$. GeoBasis-DE/BKG 2009, Google 2016. http://www.earth.google.com (November 2016).

Ho, S., Biraro, M., Muvunyi, G., Wayumba, R., 2017. Field Data Results, Version 1., its4land, KU-Leuven, Belgium
ICAO, 2011. Unmanned Aircraft Systems (UAS). Cir 328 AN/190.

Koeva, M., Muneza, M., Gevaert, C., Gerke, M., \& Nex, F., 2016. Using UAVs for map creation and updating. A case study in Rwanda, Survey Review, 1-14.

Langford, B., 1994. Nominal grouping sessions, Marketing Research, 6(3), pp.16-21.

Langford, B.E., G. Schoenfeld and G. Izzo, 2002. Nominal grouping sessions vs focus groups, Qualitative Market Research: An International Journal, 5(1), http://dx.doi.org/10.1108/13522750210414517.

Lengoiboni, M., Arnold K. Bregt, and Paul van der Molen., 2010. "Pastoralism within land administration in Kenya-The missing link. "Land Use Policy, 27.2 pp.579-588.

Lloyd, S., 2011. Applying the nominal group technique to specify the domain of a construct, Qualitative Market Research: An International Journal, 14(1), at http://www.emeraldinsight.com/doi/10.1108/135227511110993 46.

Rwanda Civil Aviation Authority, 2016. Ministerial Regulations No 01/MOS/Trans/016 of 26/04/2016 Relating to Unmanned Civil Aircraft System.

Schwering, A., Wang, J., Chipofya, M., Jan, S., Li, R., \& Broelemann, K., 2014. SketchMapia: Qualitative representations for the alignment of sketch and metric maps. Spatial Cognition \& Computation, 14(3), pp. 220-254.

Stöcker, E.C., Bennett, R.M., Nex, F.C., Gerke, M. and Zevenbergen, J.A., 2017. Review of the Current State of UAV Regulations. In: Remote Sensing: open access, 9 (2017) 5article no. 459 , p. 26

UN-HABITAT., 2012. Handling Land-Innovative Tools for Land Governance and Secure Tenure. GLTN. Nairobi.

Zevenbergen, J., Augustinus, C., Antonio, D., \& Bennett, R., 2013. Pro-poor land administration: Principles for recording the land rights of the underrepresented. Land use policy, 31, pp.595-604

Zevenbergen, J., and Bennett, R., 2015. The visible boundary: More than just a line between coordinates. In GeoTechRwanda, Kigali, Rwanda, pp 1-4.

Zevenbergen, J., De Vries, W., Bennett, R.M., 2015. Advances in Responsible Land Administration. CRC Press: Padstow, UK, p 279. 